\title{
Microstructure effect of nano-ceramic composites in nano-indentation tests
}

\author{
Zhong LING \\ LNM, Institute of Mechanics \\ Chinese Academy of Sciences \\ Beijing 100080, P.R.China \\ lingz@lnm.imech.ac.cn
}

\begin{abstract}
The Young's modulus and hardness of nanoceramic composites, $\mathrm{Al}_{2} \mathrm{O}_{3} / \mathrm{SiC}_{\mathrm{p}}$, are measured via Nanoindenter under peak loads of $3-250 \mathrm{mN}$ and peak depths of $60-920 \mathrm{~nm}$. The testing materials are $\mathrm{Al}_{2} \mathrm{O}_{3}$ and $\mathrm{Al}_{2} \mathrm{O}_{3}$ containing $\mathrm{SiC}$ particles with volume fractions, $5 \%$ and $10 \%$. The size of $\mathrm{SiC}$ particle is about $60-100 \mathrm{~nm}$. The experimental results showed that, the measured Young's modulus in current composites is higher than that of $\mathrm{Al}_{2} \mathrm{O}_{3}$ while indentation is over some depth, which related to microstructure scales in the composites. It is because of that the contact stiffness is sensitive to the microstructure of current composites. The hardness measured in two composites is depthdependant but that in $\mathrm{Al}_{2} \mathrm{O}_{3}$ seems not to be sensitive to the indentation depth.
\end{abstract}

Index Terms - ceramic composites, hardness, modulus, scaling

\section{INTRODUCTION}

Nano-ceramic composites are ceramics containing nanosize-ceramic particles of $1-5 \%$ volume fractions. The nanosize-particles dispersed in grains of the matrix would lead to a change in the fracture mode, from inter-granular to predominantly trans-granular, and to enhance fracture toughness of the composite. Among the toughening mechanisms of such particulate ceramic composites, one primary is residual stress (strain) in the matrix grain due to mismatch between the coefficients of thermal expansion (CTEs) of the ceramic matrix and second particles. Quantitative description of the ceramic composites' properties at a much smaller scale is necessary for a good understanding of the toughening mechanism.

Nanoindentation technique develops over last ten years and its principle advantage is to probe the mechanical properties of materials at the very small scale $(\mathrm{nm} \sim \mu \mathrm{m})$ during loading and unloading. In this paper, nanoindentation tests are preformed for $\mathrm{Al}_{2} \mathrm{O}_{3} / \mathrm{SiC}_{\text {nano }}$ and monolithic $\mathrm{Al}_{2} \mathrm{O}_{3}$. The investigation is focused at scaling effect in nanoindentation measurement, which relates to microstructure of the current composites.

\section{EXPERIMENTAL PROCEDURE}

\section{A. Material and Testing Conditions}

The testing materials for the present study were sintered aluminium and its composites containing $\mathrm{SiC}$ particles $\left(\mathrm{Al}_{2} \mathrm{O}_{3} / \mathrm{SiC}\right)$. The volume fractions of $\mathrm{SiC}$ particles were $5 \%$ and $10 \%$. The SiC particle size was $\sim 60-100 \mathrm{~nm}\left(d_{\mathrm{SiC}}=60\right.$ -
$100 \mathrm{~nm})$. The tested samples were in the form of plates measuring $5 \mathrm{~mm} \times 3 \mathrm{~mm} \times 3 \mathrm{~mm}$, with flat-machined parallel surfaces. Each tested surface was finely diamond-polished to a mirror-liked, scratch-free quality suitable for indentation.

Because $\mathrm{SiC}$ particles existed as a second phase in the current composite, some scaling of the microstructure of the composite would have been involved over the entire indentation process. Some microstructure scales for the original material are shown in Table I.

\section{TABLE I}

MicrostruCtURE COEFFICIENTS IN CURRENT MATERIALS

\begin{tabular}{llcc}
\hline $\mathrm{Al}_{2} \mathrm{O}_{3} / \mathrm{SiC}_{\mathrm{p}}$ & Ratio & Size & $\delta_{\text {Sic }}$ \\
\hline $\mathrm{Al}_{2} \mathrm{O}_{3}$ & balance & $-5 \mu \mathrm{m}$ & - \\
$\mathrm{Al}_{2} \mathrm{O}_{3} / \mathrm{SiC}_{\mathrm{p}}$ & $\mathrm{f}_{\mathrm{v}}=0.05$ & $60-100 \mathrm{~nm}$ & $145-242 \mathrm{~nm}$ \\
$\mathrm{Al}_{2} \mathrm{O}_{3} / \mathrm{SiC}_{\mathrm{p}}$ & $\mathrm{f}_{\mathrm{v}}=0.10$ & $60-100 \mathrm{~nm}$ & $88-147 \mathrm{~nm}$ \\
\hline
\end{tabular}

Depth-sensing tests were performed at room temperature, using a nanoindentation device with a Berkovich tip. The maximum peak loads were set as $3-300 \mathrm{mN}$, and three tests were conducted at each peak load. The recorded peak depths were about $60 \sim 920 \mathrm{~nm}$. Figure 1 presented micrograph of

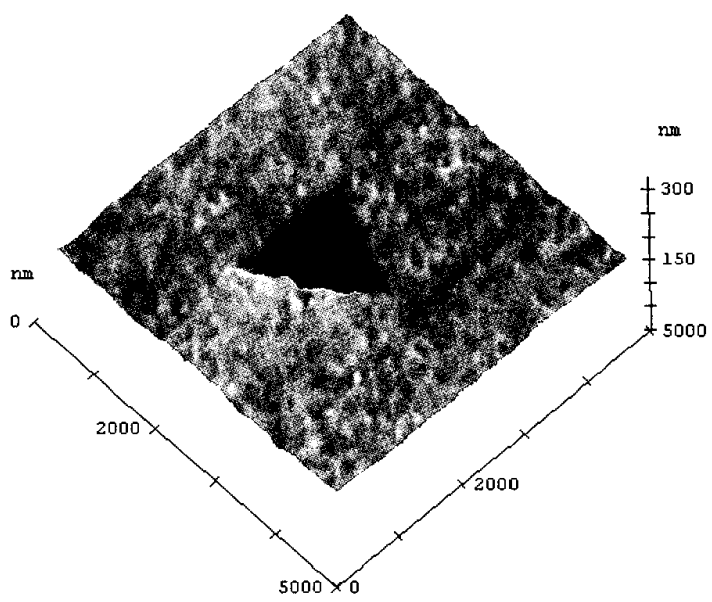

Fig. 1 AFM for an indentation on $\mathrm{Al}_{2} \mathrm{O}_{3}$ under peak load of $50 \mathrm{mN}$.

\footnotetext{
- This work is supported from National Science Foundation of China (Grant No.50172053) and the Chinese Academy of Sciences (Grant No. KJCX-SW-L2).
} 
indentation, peak load $50 \mathrm{mN}$ for $\mathrm{Al}_{2} \mathrm{O}_{3}$, under Atomic Force Microscopy (AFM).

\section{B. Experimental Results}

1) Loading Curve: The indentation curve in the nanoindentation tests is represented by the indenter load, $P$, as a function of the apparent penetrating depth, $h$. Based on the curve $P(h)$, important properties related to the apparent hardness, $H$, and Young's modulus, $E$, at a local indentation can be generally derived according to $[1,2]$ :

$$
\begin{aligned}
& P=P(h) \quad S_{m}=\left.\frac{d P}{d h}\right|_{h=h_{m}}=\frac{2}{\sqrt{\pi}} E_{r} \sqrt{A\left(h_{p}\right)} \\
& H=\frac{P_{\max }}{A\left(h_{p}\right)}, \quad h_{p}=h_{\max }-\varepsilon \frac{P_{\max }}{S_{m}}
\end{aligned}
$$
, where $S_{\mathrm{m}}$

is initial slope of the unloading curve at the maximum depth, also termed the contact stiffness; $E_{r}$ reduced modulus related to $E ; A$ the projected area of the contact surface, obtained by the method suggested in [1] for a blunt tip; $h_{p}$ the real depth of indenter; and $\varepsilon \approx 0.75$ for Berkovich tip.

The recorded indentation curves could actually be evaluated with respect to their curvatures and preliminarily pooled as apparently "soft" and "harder" locations in the microstructure of the contact surface. Figure 2 shows the entire process under peak load $250 \mathrm{mN}$ for three materials. Their load-depth curves show pronounced variation, which is the characteristic of the different microstructures of current materials.

2) Contact Stiffness: The contact stiffness, $S$, is another important property related to local heterogeneities of the material. Figure $3 \mathrm{a}$ shows relations between the contact stiffness and tip's depth for the three materials. At a depth less than $200 \mathrm{~nm}$, three materials have almost the same stiffness. With the indent-depth getting deeper, the stiffness varied significantly. Both composites, $\mathrm{Al}_{2} \mathrm{O}_{3}$ containing $\mathrm{SiC}$ particles of different volume fractions, have the same stiffness that varies linearly with the tip's depth. But the stiffness of $\mathrm{Al}_{2} \mathrm{O}_{3}$

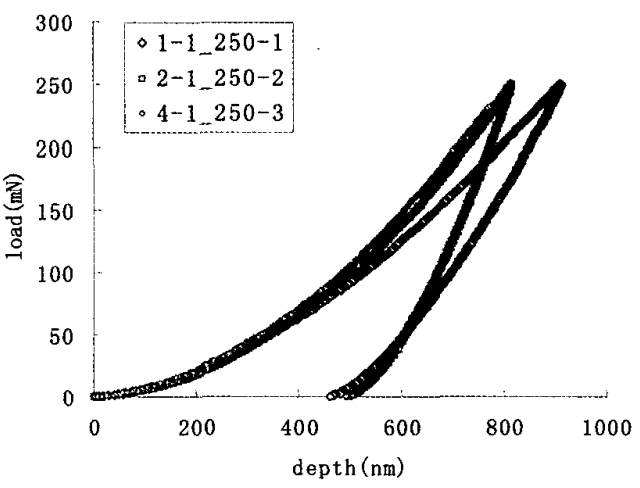

Fig.2 Typical recorded load-depth curves in nanoindentation tests for three materials (peak load $=250 \mathrm{mN}$ ). changes greatly with the tip's depths. It is similar to that appeared in surface sensitivity, $\varepsilon \frac{P_{h}}{2 S_{h}}$ Where the subscript " $h$ " indicates instant tip's depth. Fig.3b shows surface sensitivity versus tip's peak depth during the entire indentation process. At a depth less than $200 \mathrm{~nm}$, the surface sensitivities of the three materials are almost agreed each other. With the indentation getting deeper, they are changed significantly.

Noticing in the current composites, the matrix grain size was $\sim 5 \mu \mathrm{m}$, the $\mathrm{SiC}$ particle size was $\sim 60-100 \mathrm{~nm}$, and the distance between any two nearest-neighbour particles was $\sim 90-242 \mathrm{~nm}$. An indentation with a depth less than $200 \mathrm{~nm}$ could be local at a mono-phase between two nearest $\mathrm{SiC}$

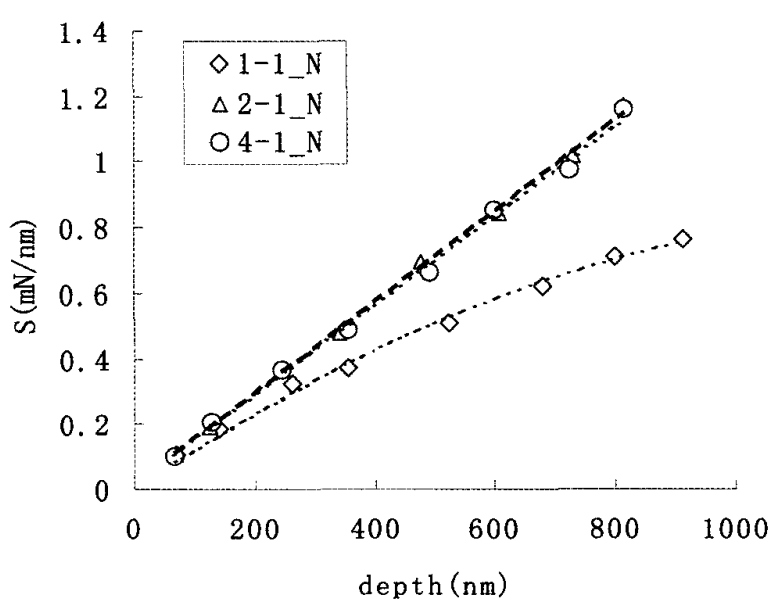

Fig.3a Contact stiffness against peak depth for three materials $\left(\diamond-\mathrm{Al}_{2} \mathrm{O}_{3}, \triangle-\mathrm{Al}_{2} \mathrm{O}_{3} / \mathrm{SiC}(5 \%), \bigcirc-\mathrm{Al}_{2} \mathrm{O}_{3} / \mathrm{SiC}(10 \%)\right)$

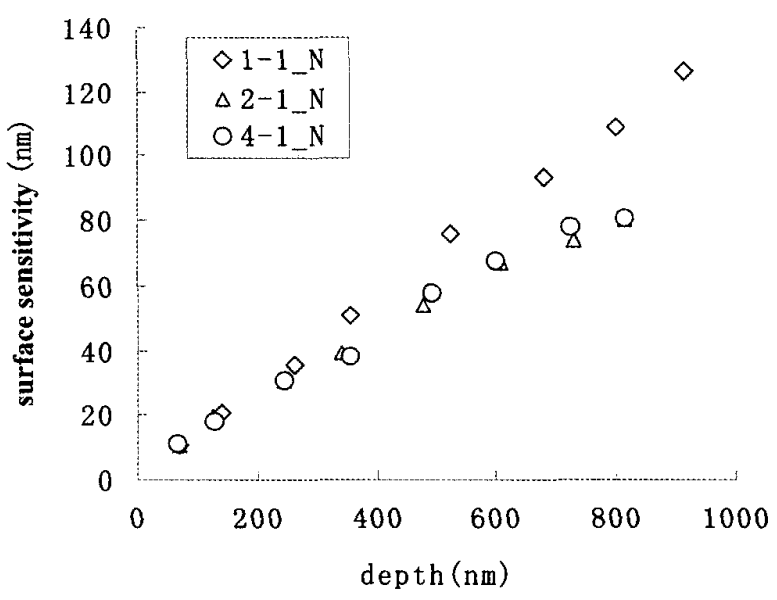

Fig. 3b Surface sensitivity against peak depth for three materials $\left(\left(\diamond-\mathrm{Al}_{2} \mathrm{O}_{3}, \triangle-\mathrm{Al}_{2} \mathrm{O}_{3} / \mathrm{SiC}(5 \%), \mathrm{O}-\mathrm{Al}_{2} \mathrm{O}_{3} / \mathrm{SiC}(10 \%)\right)\right.$ 
particles for composites. So is for the matrix material. Therefore the contact stiffness and surface sensitivities, measured at such depth range in the three materials, are likely to be in agreement.

3) Young's modulus: The essential properties of the current materials, such as Young's modulus and hardness, are measured in nanoindentation tests. Figure $4 \mathrm{a}$ showed the measured Young's modulus at different peak depths for three testing materials. At initial indentation, a depth less than $200 \mathrm{~nm}$, the magnitude of Young's modulus in the three materials seems to be the same. With indentation deeper, Young's moduli measured in two composites are higher than that in $\mathrm{Al}_{2} \mathrm{O}_{3}$. As stated above, it could be readily understood as microstructure effect resulted from of $\mathrm{SiC}$ particles in the

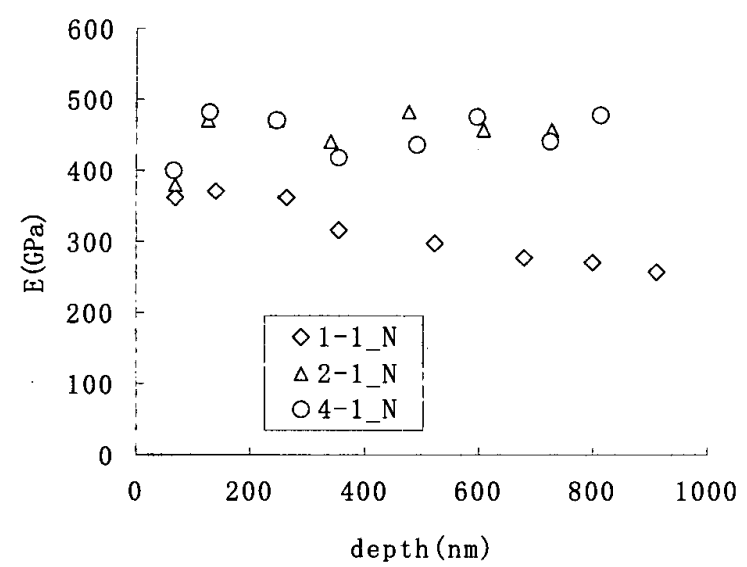

Fig.4a Young's modulus measured at different peak depths $\left(\diamond-\mathrm{Al}_{2} \mathrm{O}_{3}, \triangle-\mathrm{Al}_{2} \mathrm{O}_{3} / \mathrm{SiC}(5 \%), \bigcirc-\mathrm{Al}_{2} \mathrm{O}_{3} / \mathrm{SiC}(10 \%)\right)$

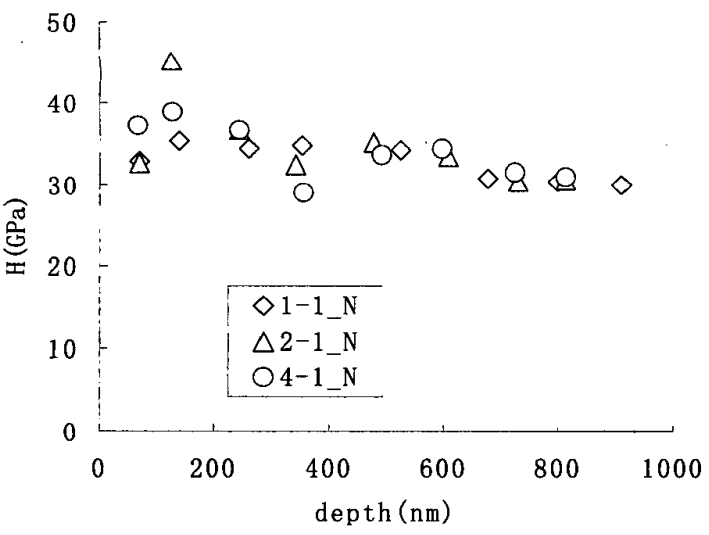

Fig.4b Measured hardness at different peak depths $\left(\diamond-\mathrm{Al}_{2} \mathrm{O}_{3}\right.$, $\left.\triangle-\mathrm{Al}_{2} \mathrm{O}_{3} / \mathrm{SiC}(5 \%), \mathrm{O}-\mathrm{Al}_{2} \mathrm{O}_{3} / \mathrm{SiC}(10 \%)\right)$ composites, based on microstructure scales (Table 1) and contact stiffness showed in Figure 3a. At the depth less than $200 \mathrm{~nm}$, the indenter is local at matrix between two nearest particles and three materials have almost the same contact stiffness. Young's modulus measured, therefore, should be as same as that of $\mathrm{Al}_{2} \mathrm{O}_{3}$. While indent gets deeper, more $\mathrm{SiC}$ particles, in composites, would make contact stiffness of the composites higher than that of $\mathrm{Al}_{2} \mathrm{O}_{3}$ (Figure 3a). And higher Young's modulus is obtained. But for both composites, their Young's modulus seems not to be sensitive to the volume fractions of SiC particles at indentation depth less than $1 \mu \mathrm{m}$.

4) Hardness: Hardness measured against the peak indentation depth is showed in Figure 4b. In three materials, hardness of two composites varied with peak indentation depth, higher at shallower indentation and lower at deeper one. But hardness measured in $\mathrm{Al}_{2} \mathrm{O}_{3}$ seems not to be varied obviously as indentation deeper. Details on the analysis to microhardness and their sensitivity to the heterogeneous microstructure of current materials have presented in [3].

\section{SUMMARY}

The present study investigated the microstructural effect in nanoindentation tests for $\mathrm{Al}_{2} \mathrm{O}_{3}$ and its composites $\mathrm{Al}_{2} \mathrm{O}_{3} / \mathrm{SiC}_{\mathrm{p}}$ ( $\mathrm{SiC}$ particles volume fractions, $5 \%$ and $10 \%$ ). The followings are deduced.

The surface sensitivity related to heterogeneous microstructure of matrix material and composites. At initial indentation of $<200 \mathrm{~nm}$, it presented the property of $\mathrm{Al}_{2} \mathrm{O}_{3}$ for mono-phase $\mathrm{Al}_{2} \mathrm{O}_{3}$ and its composites; However, as the indentation depth increased, the contact surface area increased, and more information on the heterogeneous microstructure of the current composite was revealed. The heterogeneous microstructure affected contact stiffness and surface sensitivity.

The Young's modulus measured in two composites is higher than that in $\mathrm{Al}_{2} \mathrm{O}_{3}$, which would own to the heterogeneous microstructure effects. But it is strange that the Young's modulus measured in current composites do not obviously relate to the volume fraction of $\mathrm{SiC}$ particles in the given indentation depth less $1 \mu \mathrm{m}$.

The hardness measured in both composites is more sensitive to tip's depth than that in $\mathrm{Al}_{2} \mathrm{O}_{3}$.

\section{REFERENCES}

[1] W.C. Oliver, G.M. Pharr, "An Improved Technique for Determining Hardness and Elastic Modulus Using Load and Displacement Sensing Indentation Experiments", J. Mater.Res. vol. 7 pp.1564-1583,1992.

[2] G.M.Pharr, "Measurement of mechanical properties by ultra-low load indentation," Materials Science \&Engineering, A253 pp151-159, 1998

[3] Z. Ling, X.L. Wang, "Depth-dependent Microhardness Measured in $\mathrm{Al}_{2} \mathrm{O}_{3} / \mathrm{SiC}_{\mathrm{p}}$ " (submitted) 